\title{
Indian researchers press for stricter rules to regulate 'gene-hunting'
}

New Delhi. The Indian government is coming under pressure from some of its own scientists to tighten the rules on the export of human DNA and blood samples. This follows growing evidence of the interest of foreign research groups in using India as a fruitful 'hunting-ground' for disease genes and their mutations.

Much of the pressure is coming from Indian researchers concerned that some valuable genetic information appears to be being taken from the country 'illegally' under the guise of collaborative research in human genetics.

Since 1992, the export of biological tissues has required specific clearance from the Indian Council of Medical Research (ICMR). But the council lacks sufficient powers to enforce the rule, and its officials say that they therefore feel unable to do anything about samples leaving India without their knowledge (see box below).

With its huge population of diverse cultures and significant in-breeding, India is a natural setting to look for rare genetic mutations. The Onge tribes of India, for example, have a small Y chromosome and low sperm count, while a community of 700 families in southern India suffers from a combination of osteoarthritis and dwarfism.

"Name any genetic disorder and we have the mutations ," says Samir Brahmachari, professor of molecular biophysics at the Indian Institute of Science in Bangalore. "If you are looking for twins, we have plenty."

India also provides scope for "differential genome comparison". In West Bengal, for instance, where cholera is endemic, a large group of Family affairs: the incidence of large families and individuals appears to be immune to in-breeding makes India attractive to geneticists. the disease. The gene responsible, which may eventually lead to a valuable commercial product, is now being sought at a laboratory in Calcutta using sophisticated equipment donated without strings by the government of Japan.

In addition, Indian geneticists point out that, with family structures crumbling in the West, the data about large families required for linkage studies are available only in India because China - the other populous country - is not easily accessible.

\author{
IMAGE \\ UNAVAILABLE \\ FOR COPYRIGHT \\ REASONS
}

But the growing interest of foreign research groups is prompting the Department of Biotechnology (DBT) to tighten rules on the export of genetic data, and to draw up guidelines for international collaboration before the launch of the Human Genome Diversity Project (HGDP), a global effort to study genetic variations in Homo sapiens (see Nature 377, 372; 1995).

The latter project is planning to study blood samples taken from indigenous populations worldwide, including 23 ethnic

\section{Scientists challenged over 'unauthorized' export of data}

New Delhi \& Washington. Researchers from the US National Institutes of Health (NIH) have been accused of violating an Indian government regulation forbidding the export of biological material without specific permission from the Indian Council of Medical Research (ICMR).

According to a spokesman for the ICMR, the NIH's National Eye Institute (NEI), which is collecting DNA and blood samples from patients at major private eye hospitals in India, has not obtained the authorization required to take samples out of the country, and is therefore acting "illegally".

But Carl Kupfer, the director of the $\mathrm{NEI}$, while confirming that the institute is receiving blood samples from India, points out that the research protocols have been cleared by review boards in both India and the United States. He adds that neither the NEI, nor the Indian hospital with which it is collaborating, is aware of any requirement to clear the arrangement with the ICMR.

The US scientists are searching for the gene or genes that cause retinitis pigmentosa (RP), otherwise known as night blindness. India is an ideal social setting for mapping the location of the gene because of its large families several members of which can suffer from RP - and the high incidence of intermarriage.

The NEI is already collecting samples from L. V. Prasad (LVP) Eye Hospital in Hyderabad, and is engaged in discussions to collect similar samples from three others, the Sankar Nethralaya in Madras, Little Flower Medical Centre in Angamally in Kerala, and an eye hospital in Amritsar. The last of these has a large database with details of more than 20,000 patients suffering from RP and congenital cataract.

According to Subadra Jalali, a surgeon at the LVP hospital, blood samples of 80 members belonging to six RP-affected families have already been sent to the $\mathrm{NIH}$, and the hospital has agreed to provide such data on 20 families over a period of three years. In return, says Jalali, the NIH will provide the hospital with $\$ 180,000$ to cover payments to patients who give blood

"voluntarily".

Government officials claim that NIH is not the only foreign body which, they say, is exporting without authorization Indian blood samples. Researchers at the Duke University Medical Centre in Durham, North Carolina, for example, are close to identifying the mutation responsible for juvenile myoclonic epilepsy (JME) which accounts for ten per cent of all epilepsies.

The US scientists were fortunate to find a clinician in a Delhi hospital who provided them with blood samples from what is said to be the world's largest family with JME. Nine of its 30 members are affected.

In response to the charge that US researchers are bypassing the views of leading Indian geneticists and ignoring local export regulations, Kupfer points out that the NEI project is being carried out in collaboration with J. S. Murty of the University of Osmania at Hyderabad, a past-president of the Indian Society of Human Genetics, and that it includes a strong training component.

K. S. Jayaraman and Colin Macilwain 
$\checkmark$ groups from the Indian subcontinent. But several members of DBT's own task force on human genetics warn that, in the absence of strict regulations, the country's unique human genetic diversity might be exploited by foreigners without India receiving any tangible benefits.

Last month, the Indian Society of Human Genetics (ISHG), meeting in Calcutta, drew up guidelines calling for a ban on transport of "whole blood, cell-lines, DNA, skeletal, and fossil material" without a formal agreement between collaborating parties.

According to the society, any such agreement should be approved by the appropriate government agencies and should clearly specify "the objectives of the project and the anticipated scientific, material, and economic benefits and the manner that they are to be shared both at present and in future".

Partha Mazumdar of the Indian Statistical Institute in Calcutta, a member of the national committee on HGDP, says that even if DNA is shared for research purposes, "subsequent transfer must clearly be stopped, as the end-use of the specimen cannot be overseen".

But some clinicians disagree, arguing that the results of the project will eventually benefit India's population. "We have clinical materials, [Western countries] have the technology, and we can work together with a good understanding," says Satish Jain, a neurologist at the All India Institute of Medical Sciences in New Delhi.

Jain, who is sending blood samples taken from epileptic patients to researchers in the United States, Canada and Australia without ICMR clearance, says he believes that government regulations will kill collaborative projects with foreign research teams.

In general, Indian scientists agree that collaboration with Western research groups is essential, as there are very few laboratories in India sufficiently well equipped to study genetic disorders in the population. But there is concern that the results of collaboration may prove one-sided.

"It must be on an equal footing, and on a formal basis," says Brahmachari, a member of the DBT task force.

Indian scientists say that the global map of genome diversity will be incomplete without mutation data from regions such as India and that, while the government should not obstruct sharing of the data, its potential commercial value (and ownership) should be protected by appropriate policies.

The DBT is unlikely to announce a policy decision until a new secretary is appointed to succeed Chittaranjan Bhatia, its former head, who retired in December. Before his departure, Bhatia had described the department's mission as being to "convert India's genetic wealth into economic wealth".

To this end, the DBT has already begun its own programme on human genome diversity research. Four regions have been chosen for studies to identify genes responsible for diseases.

K. S. Jayaraman

\section{Internet struggles to connect around the Asia-Pacific rim}

Hong Kong \& Tokyo. Both the private sector and government agencies in the Asia-Pacific region are moving rapidly to increase the capacity of Internet connections between countries on the Western Pacific rim. But many observers fear that their efforts may be premature, given the relatively undeveloped level of computer networks in many countries of the region.

Last month, Asia Internet Holding Company Ltd, a new joint venture set up between companies in Japan, Hong Kong and Singapore, took out a lease on a highcapacity Internet link between Japan and Hong Kong, and announced that it plans to lease further lines, in order to create an 'Asian backbone' running between Japan, Hong Kong and Singapore.

In addition, the Japanese government is floating the ambitious ideas of building a gigabit capacity network linking researchers of the Asia-Pacific region, following discus-

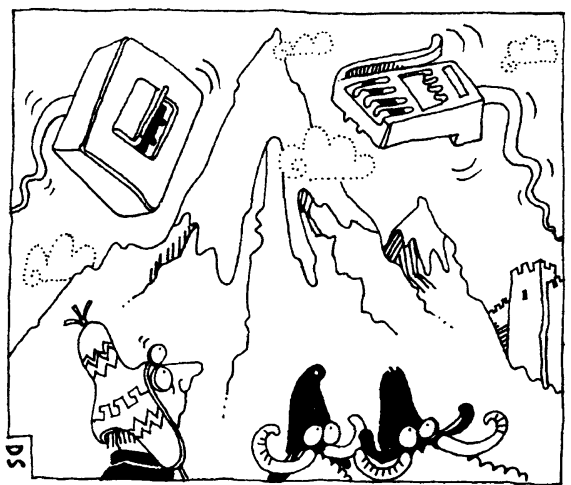

sions during a meeting of science ministers of the Asia Pacific Economic Cooperation (APEC) forum in Beijing last year.

Japan, South Korea, Taiwan, Hong Kong, Singapore and Australia are relatively well connected to the Internet through individual high-capacity links to the United States. But the capacity of connections between Western Pacific rim nations is limited, and most intraregional traffic is therefore routed via the West coast of the United States - one reason why some of the trans-Pacific links, particularly those between Japan and the United States, cannot meet demand.

Asia Internet Holding Company was set up last October by Internet Initiative Japan (IIJ), one of Japan's new commercial providers of Internet access, Sumitomo Corporation, a large Japanese general trading company, Pacific Internet of Singaporeowned Sembawang Corporation, a statebacked shipbuilding company, and Hong Kong Supernet Ltd, a commercial access provider set up by Hong Kong University of Science and Technology (HKUST).

The company has leased a line capable of transmitting 768 kilobits per second between Japan and Hong Kong. This will be upgraded to $\mathrm{T} 1$ capacity (1.2 megabits per second) this month, and the consortium also plans to establish another high-capacity link between Japan and Singapore in the near future, according to Eugene Wong of HKUST, who set up Supernet.

The joint venture has yet to be granted operating licences from all the governments concerned. But Wong says customers are already queuing up to use the service, and that the new company expects business to flourish with the rapid growth of Asia's economies.

Other Internet providers in Japan remain sceptical about whether the need yet exists for such links, and are concentrating on expanding trans-Pacific capacity. But Wong says he is convinced that the joint venture will have a "catalytic" effect on the development of the Internet in Asia, and that the high capacity lines will provide a "natural electronic backbone".

The Japanese government is also keen to develop computer networks in the Asia-Pacific region. Japan's Science and Technology Agency (STA) will host a symposium next month in Tsukuba science city to discuss the prospects for a gigabit network linking the Asia-Pacific region. But such ambitious ideas represent a major step from the present level of computer networks in many Asian countries.

China, for example, installed its first 64kilobit link to the outside world only in 1994, and the Chinese government may well hold back further development of the country's computer links by trying to restrict the commercial development of the Internet, just at a time when the private sector is becoming the driving force behind expansion of the network elsewhere in the world.

Last week, China's State Council announced plans for new regulations to strengthen government control of online links to the outside world. This follows a decree passed by the Communist party and the state council at the end of December acknowledging that the Internet is important for the economy and science, but warning that it threatens to usher in pornography and other "harmful materials".

Another reflection of the primitive state of Internet connections in Asia is the fact that the STA is planning to distribute information about Japan's government research institutes to countries in the AsiaPacific region by CD-ROM rather than the Internet. The sum of $¥ 130$ million (US\$1.2 million) has been set aside for this purpose in the agency's budget for 1996.

David Swinbanks 